\title{
Effects of temperature and reaction time on yield and properties of biocrude oil produced by hydrothermal liquefaction of Spirulina platensis
}

\author{
Weene S. Villaver ${ }^{\mathrm{a}}$, Rowena B. Carpio ${ }^{\mathrm{a}, \mathrm{b}}$, Kristian July Yap ${ }^{\mathrm{a}}$, Rizalinda L. de \\ Leon $^{\mathrm{a}}$ \\ ${ }^{a}$ University of the Philippines Diliman - Quezon City 1100, Philippines \\ ${ }^{b}$ University of the Philippines Los Baños - Laguna 4031, Philippines
}

\begin{abstract}
Hydrothermal liquefaction (HTL) is a process technology suited for converting wet biomass, like microalgae, into biocrude oil. This study investigates the effects of temperature and reaction time on the mass yield and the properties of HTL biocrude oil such as higher heating value (HHV) and composition. Spirulina platensis, a microalgae species, is used as feedstock. Slurry prepared at $30 \%$ dry weight is processed in $5-\mathrm{mL}$ mini-reactors. Temperatures are set at $280^{\circ} \mathrm{C}, 320^{\circ} \mathrm{C}$, and $350^{\circ} \mathrm{C}$ using a temperature-controlled sandbath. Reaction times are varied at 15 mins, 30 mins, and 45 mins. Biocrude oil is produced and separated using dichloromethane (DCM) as solvent. The mass yield of biocrude oil varies depending on temperature and reaction time ranging from $29.6 \%$ to $44.8 \%$ by mass, dry ash-free (daf) basis. Higher mass yield is observed at the lowest temperature setting of $280^{\circ} \mathrm{C}$. The HHV is measured using bomb calorimeter and calculated using Dulong's formula. The HHV ranges from $31.5 \mathrm{MJ} / \mathrm{kg}$ to $37 \mathrm{MJ} / \mathrm{kg}$. Highest $\mathrm{HHV}$ is obtained for biocrude oil at $350^{\circ} \mathrm{C}$ and 45 mins reaction time. The highest energy recovery is $76.8 \%$, which is attained at $280^{\circ} \mathrm{C}$ and 45 mins. Elemental analysis and GC-MS analysis are conducted to analyze the composition of biocrude oil produced. The N/C and O/C ratios of HTL biocrude oil are reduced in all experimental conditions. Nitrogen content is lowest at $350^{\circ} \mathrm{C}$ and 30 mins to 45 mins reaction time.
\end{abstract}

Keywords: Hydrothermal liquefaction, biocrude oil, microalgae, Spirulina platensis

\section{Introduction}

Fossils are still the source of the crude from which the fuels used in the world today is derived.[1] Though it is continually formed, it is considered as non-renewable resource due to its long period of production. With the high demand and continually increasing demand for fuels, crisis on fossil fuel shortage is inevitable. Overdependence on it even brought other problems like environmental pollution.[2] So, alternatives to fossil fuels are studied to cope with the present and future demand.[3] This is the rise of studies on biofuels, which are fuels that come from biomass. [4] Biomass is abundant and is renewable energy resource.[5] The early rise of biofuels considers biomass that is used in food sectors. Biodiesel produced from terrestrial vegetation and animal lipids makes up just 3\% of the total diesel consumed and it occupies a large land area and competes with food supply, which leads to other issues.[6] Thus, the increased interest on microalgae as the biomass source for fuels.[7] Microalgae is a microscopic photosynthetic organism that is considered as versatile biological cell factories. It has faster growth rates and high area-specific yields. It is photoautotrophic organism that directly converts solar energy into chemical energy. In this process, high photosynthetic efficiency and short cultivation cycle can be done for microalgae.[8] Microalgae is primarily comprised of proteins, carbohydrates, fats and nucleic acids in varying proportions. It can grow in saline or freshwater or in agricultural wastewater. It can also be cultivated in non-arable lands so there is potential for a lower environmental impact and little competition for food.[2] Microalgae usually has very high water content of around $80 \% 90 \%$ by weight.[8]

* Manuscript received August 15, 2017; revised December 20, 2017.

Corresponding author. E-mail address: weene.villaver@upd.edu.ph.

doi: 10.12720/sgce.7.1.32-41 
Thermal processes are significant in converting biomass to biofuel.[4] Depending on the type of biomass, a suitable process must be carried out. Since all parts of microalgae can be processed and converted to biocrude oil, drying is no longer needed. Using lipid extraction and trans-esterification technologies used in the production of biodiesel from a wet biomass are energy intensive. Wet process like hydrothermal liquefaction (HTL) is found to be suitable in converting wet biomass like microalgae into biofuel.[9] HTL has the potential to lessen the energy required in processing as drying is eliminated.[10], [11] It is considered as a promising technology for converting wet biomass to biofuel.[12], [13] HTL is a process of converting biomass in sub-critical water into biocrude or bio-oil. HTL is carried out between 280 to $370 \mathrm{deg} \mathrm{C}$ and high pressures of 10-25 MPa.[5] Under sub-critical conditions, depolymerization and repolymerization of complex molecules occur to produce biocrude.[14] Among the species studied in past researches include Botryococcus braunii, Nannochloropsis oculata, Chlorella vulgaris, Porphyridium cruentum, Spirulina, Desmodesmus sp., Tetraselmis sp, Dunaliella salina, Dunaliella tertiolecta among others. [8]

In this study, Spirulina platensis is the microalgae species used as biomass. Cultivation of Spirulina has a high yield. It has around $60 \%$ protein by dry weight. [15] Investigation on the effects of temperature and reaction time on the yield and properties of HTL biocrude oil will help in the further development of the biocrude oil production.

\section{Methodology}

\subsection{Materials and set-up}

Microalgae feedstock is acquired from Superfoods Inc., a local supplier of Spirulina powder. Proximate analysis is conducted according to modified ASTM D1762 to determine the ash, moisture, fixed carbon and volatile matter content of microalgae. Ultimate analysis is carried out by combustion method (LECO Organic Application). The oxygen content is calculated based on the determined composition of $\mathrm{C}, \mathrm{H}, \mathrm{N}$, and $\mathrm{S}$. Ash and moisture are accounted for the dry ash-free basis calculations in the yield of biocrude. Dichloromethane (DCM) is the solvent used for product separation after HTL. The choice of solvent is based on the affinity to dissolve the biocrude resulting to separation from polar aqueous products of HTL. The reactors used are stainless steel Swagelok 316 unions and caps assembly. Volume capacity is $5 \mathrm{~mL}$. A fabricated sand bath made of stainless steel and insulated with ceramic fiber and equipped with $2 \mathrm{~kW}$ incoloy heater is used in the HTL process. A temperature controller with automatic and manual control option monitors and controls the heating of the sand bath based on set temperature. Type $\mathrm{K}$ thermocouple sensor is used to measure the temperature. A data logger is also included in the setup to monitor and record the temperature readings.

\subsection{Procedure}

Microalgae slurry is prepared by adding deionized water to a measured powdered microalgae. Target concentration of slurry is $30 \%$ by weight. The loading is selected based on the expected range of yield, the amount needed for testing and analysis and the capacity of the reactor used. All weights of reactors used before and after the slurry was put in are accounted. Reactors are made sure to be tightly closed to avoid leakage and spillage during HTL. The sandbath is first heated to the target temperature (280, 320, or $350 \mathrm{deg}$ C). Once the target temperature is reached, the reactors with the microalgae slurry are buried and heated in the sand bath. The temperature of the reactors is continually monitored and recorded by the data logger. Once target temperature is reached, monitoring of reaction time at particular temperature condition is started. The reactors are removed after the target reaction time is reached (15 mins, 30 mins, or 45 mins). Since reactors are extremely hot, tongs are used to take it out of the sand bath and then are quenched in water at ambient temperature. The reactors are allowed to cool down at least for an hour before proceeding to product separation. Expected products of HTL are biocrude oil, aqueous products, solid residue and gaseous products. Due to limitations of reactors used, the gas products are not collected. 
After opening the reactors, the gas is just carefully released. The solid residue, the aqueous product, and biocrude products proceeds to filtration. Whatman 41 Ashless filter paper is used in the filtration. Solid residues are trapped as the products inside the reactor are poured into the funnel with filter. Since the produced biocrude oil is viscous, it does not easily flow out of the reactor. Small aliquots of DCM solvent are added to dissolve the biocrude and wash the reactor. The biocrude oil dissolved in DCM is then poured and allowed to pass through the filter to remove any remaining solids. DCM washing is continued until a clear solvent is poured out from the reactor, which means all biocrude oil is removed. The reactors after washing with DCM are dried and weighed to make sure as well that all products are removed.

The residue remains in the filter and is dried. The collected products after removal of solids are the aqueous and biocrude with DCM. These products are separated by liquid extraction since the two do not mix due to polarity. The aqueous phase is on top of the biocrude oil with DCM. After separation of the aqueous phase, the biocrude with DCM is further separated by evaporation of DCM in the fumehood. Testing and analyses are performed with the biocrude oil product.

\subsection{Analytical methods}

\subsubsection{Mass yield determination}

The $\%$ mass yield of biocrude is calculated using the mass of biocrude oil product and the mass of the dried and ash-free feedstock. [16] The following formula is used.

$\%$ mass yield $=\frac{\text { mass of biocrude product }}{\text { mass of microalgae feedstock in dryash }- \text { free basis }} \times 100 \%$

The percent weight of moisture and ash content of Spirulina is determined during feedstock characterization. This percentage is multiplied to the weighed amount of microalgae feedstock and the values obtained are subtracted to the amount of feedstock used during the slurry preparation. The mass of biocrude product is determined from the constant weight of biocrude after all DCM has been evaporated.

\subsubsection{Elemental ratios}

Using the weight percentages of the elements $\mathrm{C}, \mathrm{H}, \mathrm{O}, \mathrm{N}$ and its corresponding atomic weights, elemental ratios are calculated. Equations below are used.

$$
\frac{H}{C}=\frac{\% \frac{w}{w} H}{\% \frac{w}{w} C} \times\left(\frac{12}{1}\right) \quad \frac{O}{C}=\frac{\% \frac{w}{w} O}{\% \frac{w}{w} C} \times\left(\frac{12}{16}\right) \quad \frac{H}{C}=\frac{\% \frac{w}{w} N}{\% \frac{w}{w} C} \times\left(\frac{12}{14}\right)
$$

\subsubsection{Higher heating value (HHV) determination}

HHV is specifically defined as the amount of heat that is released when the fuel undergoes combustion and the products have returned back to $25 \mathrm{deg} \mathrm{C}$ temperature. It takes account the latent heat of vaporization of water in the products of combustion. In this study, a Parr 6200 Bomb Calorimeter is used to measure the HHV of biocrude oil.

The elemental composition of the biocrude samples is also analyzed using combustion method. Using the carbon, hydrogen, and nitrogen $(\mathrm{C}, \mathrm{H}, \mathrm{N})$ weight percentages obtained from analysis, the weight percentage of oxygen $(\mathrm{O})$ is calculated, assuming that sulfur (S) content is negligible.[17] HHV is estimated using Dulong's formula [18] as written below:

$H H V=0.338 C+1.428\left(H-\frac{O}{8}\right)+0.095 S$

The calculated HHV is compared to the measured HHV. 


\subsubsection{Energy yield}

Energy yield is defined as the amount of energy recovered by the biocrude product relative to the original energy content carried by the amount of feedstock that goes through the HTL process. The calculation is done as follows:

$\%$ energy yield $=\frac{(\text { HHV of biocrude oil product }) x(\text { mass of biocrude oil })}{(\text { HHV of feedstock }) \times(\text { mass of feedstock }, \text { daf })} \times 100$

\subsubsection{GC-MS analysis}

Gas chromatogram-mass spectroscopy (GC-MS) is performed to analyze the chemical composition of the biocrude oil product.[11] Preparation of biocrude samples is done prior to injection to the GC-MS equipment. The clean biocrude oil is washed with DCM, allowed to pass through high purity silica gel and dried using nitrogen gas. It is then analyzed in Shimadzu GC-MS equipment. Hexane is used as the solvent to dilute the biocrude sample during GCMS analysis. Settings of GCMS are as follows: injector is set at $280 \mathrm{deg} \mathrm{C}$, initial temperature is at $50 \mathrm{deg} \mathrm{C}$ (held $1 / \mathrm{min}$ ) at constant rate of $10 \mathrm{deg} \mathrm{C} / \mathrm{min}$ until 250 deg C. Split ratio is 1:0, holding time is $9 \mathrm{~min}$, column flow of $1.4 \mathrm{~mL} / \mathrm{min}, 40$ to $450 \mathrm{~m} / \mathrm{z} \mathrm{MS}$ detector scan, solvent cut time of $3 \mathrm{mins}$, ion source and interface line temperature at $200 \& 300 \mathrm{deg} \mathrm{C}$, respectively.

\section{Results and Discussion}

\subsection{Effects of temperature and reaction time on mass yield}

The yield of biocrude oil ranges from $28.5 \%$ to $46.2 \%$ based on the runs performed at various temperature and reaction time. The lowest average \%mass yield value is $29.6 \% \pm 1.6 \%$, obtained at 350 $\operatorname{deg} \mathrm{C}$ and 15 mins reaction time. The highest mass yield observed is $44.8 \% \pm 1.9 \%$ at $280 \mathrm{deg} \mathrm{C}$ and 30 mins. It is observed that at set temperature of $280 \mathrm{deg} \mathrm{C}$, the biocrude yield is higher compared to both that of higher temperature settings of $320 \mathrm{deg} C$ and that of $350 \mathrm{deg} C$. This can be seen in the plot of the yield vs time at different conditions in Figure 1.

It can be observed that at the same reaction time, yields at $280 \mathrm{deg} \mathrm{C}$ have the highest yields. Across time, span of 15 mins to 45 mins reaction time, there is not much difference on the biocrude yield at 320 $\operatorname{deg} \mathrm{C}$ and $350 \mathrm{deg} \mathrm{C}$. This can be inferred from the overlaps of the error bars of yields at $320 \mathrm{deg} \mathrm{C}$ and $350 \mathrm{deg}$ C. Only the yields of biocrude at $280 \mathrm{deg} \mathrm{C}$ vary with the reaction time. One reason for this observation is probably because at higher temperature, the biocrude is thermally converted to gaseous molecules. Polymerization may not be the dominant reaction at $320 \mathrm{deg} \mathrm{C} \& 350 \mathrm{deg} \mathrm{C}$ thus conversion to other components in aqueous and gaseous phases may have been favored. Another study showed that above $300 \mathrm{deg} \mathrm{C}$, the critical temperature of water, lesser biocrude are produced.[18]

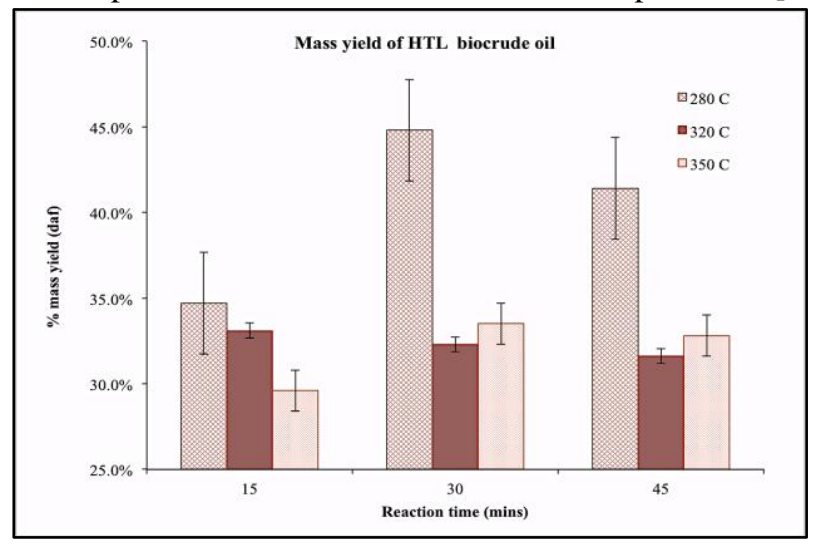

Figure 1. Mass yield of HTL biocrude oil at different conditions 
Figure 2 shows the distribution of HTL products at different operating conditions.

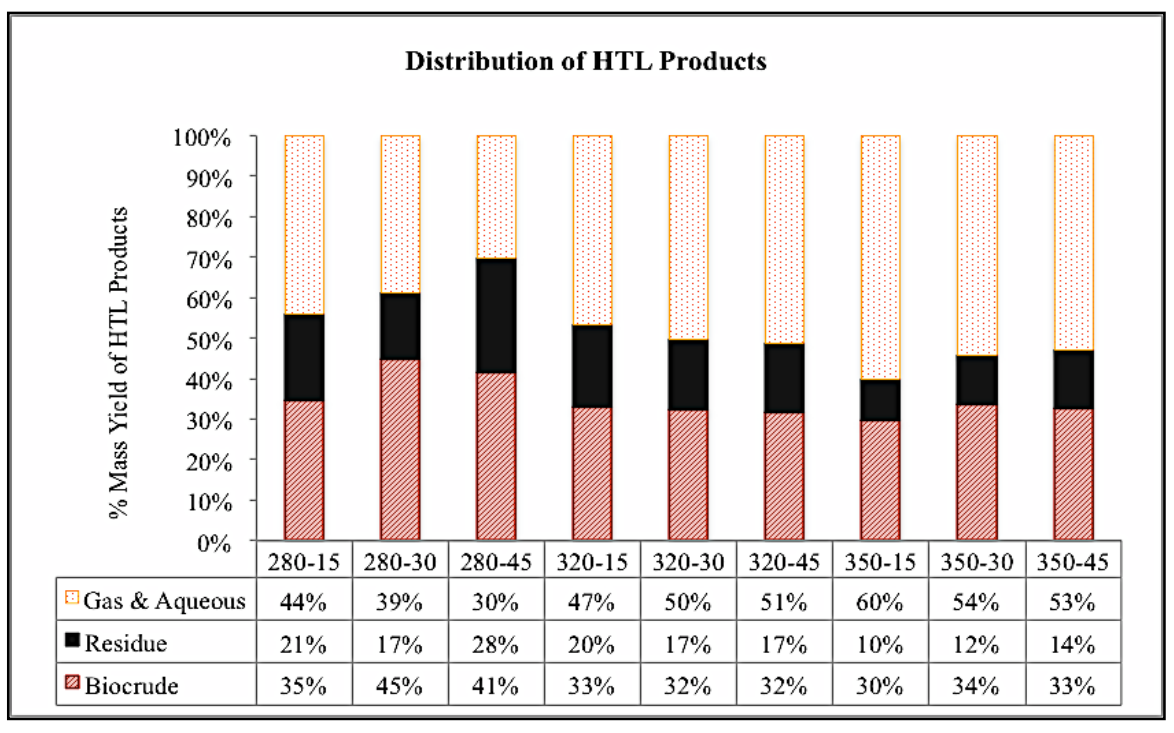

Figure 2. Distribution of HTL products at different conditions

The aqueous product and the gaseous products are added since some of the aqueous products evaporated during the separation process. Horizontal axis labels correspond to temperature of $280 \mathrm{deg} C$ and reaction times of $15 \mathrm{mins}, 30 \mathrm{mins}$ and $45 \mathrm{mins}$; $320 \mathrm{deg} \mathrm{C}$ and reaction times of $15 \mathrm{mins}, 30 \mathrm{mins}$ and 45 mins; and lastly at temperature of $350 \mathrm{deg} C$ and reaction times of 15 mins, 30 mins and 45 mins, respectively. The $\%$ mass yield of products shown at vertical axis is in dry ash-free basis. The average biocrude yield ranges from 30 to $45 \%$ mass yield. High biocrude yield is observed at low temperature. The residue yield ranges from $10 \%$ to $21 \%$ by weight. More residues are observed at lower temperature than at higher temperature. Total yield of gaseous and aqueous products amounted to $30 \%$ to $60 \%$ by weight. Gaseous and aqueous products are produced at higher temperature. The reactions forming more gases and compounds soluble to aqueous phase seem to be favored at higher temperature.

\subsection{Effects of temperature and reaction time on HHV and energy yield}

Greater HHV is desirable for fuel products. HHV of biomass can be improved by further processing. Drying or removing the moisture or water content of the material increases the combustibility of the material thus a higher HHV is expected. However, a balance on the mass yield of product and the HHV of the product must be considered to have an overall positive contribution or impact. Higher yield with greater HHV is targeted. With this, energy yield is calculated.

HHV is measured using a bomb calorimeter. This is performed for the biocrude products. Due to limitations on the amount of biocrude sample analyzed in bomb calorimeter, the measured HHV values are compared to that of calculated HHV. This is to at least see that the HHV obtained and considered in further calculations is acceptable. Based on the results, HHV measured for the biocrude ranges from 27 $\mathrm{MJ} / \mathrm{kg}$ to $37 \mathrm{MJ} / \mathrm{kg}$. It is found to be comparable to that of calculated HHV. Assumption that the sulfur content of produced biocrude oil is negligible is also justified by a very small difference of $0.06 \mathrm{MJ} / \mathrm{kg}$ or $0.16 \%$ to $0.19 \%$ in the HHV calculated. Initial amount of sulfur in the feedstock is $0.632 \%$ by weight. So for the HHV calculation, insignificant contribution of sulfur is considered. 
Table 1. Calculated HHV and energy yield of HTL biocrude oils produced at different conditions

\begin{tabular}{cccc}
\hline $\begin{array}{c}\text { Temperature } \\
\text { C }\end{array}$ & $\begin{array}{c}\text { Reaction time, } \\
\text { mins }\end{array}$ & $\begin{array}{c}\text { HHV } \\
\text { MJ/kg }\end{array}$ & Energy Yield, \% \\
\hline 280 & 15 & 31.72 & $54 \%$ \\
280 & 30 & 31.49 & $75 \%$ \\
280 & 45 & 33.18 & $77 \%$ \\
320 & 15 & 32.82 & $62 \%$ \\
320 & 30 & 32.38 & $61 \%$ \\
320 & 45 & 33.73 & $59 \%$ \\
350 & 15 & 33.13 & $56 \%$ \\
350 & 30 & 32.11 & $65 \%$ \\
350 & 45 & 36.99 & $61 \%$ \\
\hline
\end{tabular}

Table 1 shows the HHV and the energy yield of HTL biocrude at different operating conditions. It is observed that at $15 \mathrm{mins}$ reaction time, there is no significant difference between the HHV values at 320 $\operatorname{deg} \mathrm{C}$ and $350 \mathrm{deg} \mathrm{C}$. Looking at the reaction time of $30 \mathrm{mins}$, there is also no significant difference on the HHV values of biocrude processed at $280 \mathrm{deg} \mathrm{C}, 320 \mathrm{deg} \mathrm{C}$, and $350 \mathrm{deg}$ C. At 45 mins reaction time, $\mathrm{HHV}$ of biocrude at $280 \mathrm{deg} \mathrm{C}$ and $320 \mathrm{deg} \mathrm{C}$ have no significant change. However, the HHV at $350 \mathrm{deg}$ $\mathrm{C}$ and 45 mins shows a large significant change in HHV. It is important to note that this is at the highest temperature and longest reaction time. The lowest HHV value is possessed by the biocrude processed at $280 \operatorname{deg} \mathrm{C}$ and $320 \mathrm{deg} \mathrm{C}$, both at 15 mins reaction time.

At medium temperature condition, the energy yields of biocrude oil across time, 15 mins to 45 mins, are almost the same. It has the same effect across time. It can be observed also that the energy yields for biocrude at 30 mins and 45 mins reaction time are almost the same for biocrude processed at similar temperature. Implication for this is when processing at the same temperature, since the impact of $320 \mathrm{deg}$ $\mathrm{C}$ is the same as at $350 \mathrm{deg} \mathrm{C}$, going for the $30 \mathrm{mins}$ reaction time condition is enough. The high-energy yields are observed in the biocrude subjected to temperature of $280 \mathrm{deg} C$ and at $30 \mathrm{mins}$ and $45 \mathrm{mins}$ reaction time. Since there is not much difference on the HHV of the biocrude at different times but has significant difference on the mass yields in favor of lower temperature, the overall impact as reflected in the energy yield is big at lower temperature condition which is $280 \mathrm{deg} \mathrm{C}$ and the longer time of reaction which is at 30mins and 45 mins. Energy yield of biocrude processed at $280 \mathrm{deg} \mathrm{C}$ is observed to be increasing, as the reaction time takes longer. This is supported by the trends of mass yield and HHV for $280 \mathrm{deg}$ C. Across time, mass yield may have no significant difference but the HHV is greater at longer times. Thus, resulting to higher energy yield for biocrude processed at $280 \mathrm{deg} \mathrm{C}$ at longer reaction times.

\subsection{Effects on composition based on elemental analysis}

Percent composition of carbon in all biocrude is higher since carbon is the most possible component retained in the biomass product during the process. Hydrocarbons are the bulk of the components in the biocrude. Spirulina has $45.40 \% \mathrm{w} / \mathrm{w}$ carbon. The biocrude produced by HTL have increased \% composition of carbon. Carbon also has high contribution to the higher heating value of the biomass. The $\%$ composition of nitrogen is significantly decreased in the produced biocrude oil via HTL. It is then reduced after HTL in all conditions. Highest nitrogen composition analyzed is $4.73 \% \mathrm{w} / \mathrm{w}$ at $280 \mathrm{deg} \mathrm{C}$ and 30 mins reaction time. Lowest nitrogen composition is observed in the biocrude produced at $350 \mathrm{deg}$ $\mathrm{C}$ and 30 mins and 45 mins reaction time, which is at the highest temperature and longest reaction time conditions. Possible reaction is the conversion to compounds soluble in the aqueous phase or to gaseous 
products, which is favored at higher temperatures. The \% composition of hydrogen in the feedstock is $6.82 \% \mathrm{w} / \mathrm{w}$. For the biocrude, $\%$ composition varies from the $9 \% \mathrm{w} / \mathrm{w}$ to $11.6 \% \mathrm{w} / \mathrm{w}$. Lowest composition of $\mathrm{H}$ is found in the biocrude at $280 \mathrm{deg} \mathrm{C}$ and $30 \mathrm{mins}$ reaction time. The highest \%w/w of $\mathrm{H}$ is in the biocrude at $350 \mathrm{deg} \mathrm{C}$ and 45 mins. The higher value of $\mathrm{H}$ may give the fuel better quality, as high ratio of $\mathrm{H} / \mathrm{C}$ is preferred for fuels. Source of hydrogen for the reactions that possibly occur during the hydrothermal liquefaction is the water medium used. Oxygen composition in all biocrude oils is also reduced. This is expected as the process of converting the biomass to biofuel would mean reducing the amount of present oxygen thus giving a lower $\mathrm{O} / \mathrm{C}$ value for fuels, which means better quality of fuel. In the biocrude oils analyzed, low oxygen composition is observed in the biocrude processed at $350 \mathrm{deg} \mathrm{C}$ and $45 \mathrm{mins}$.
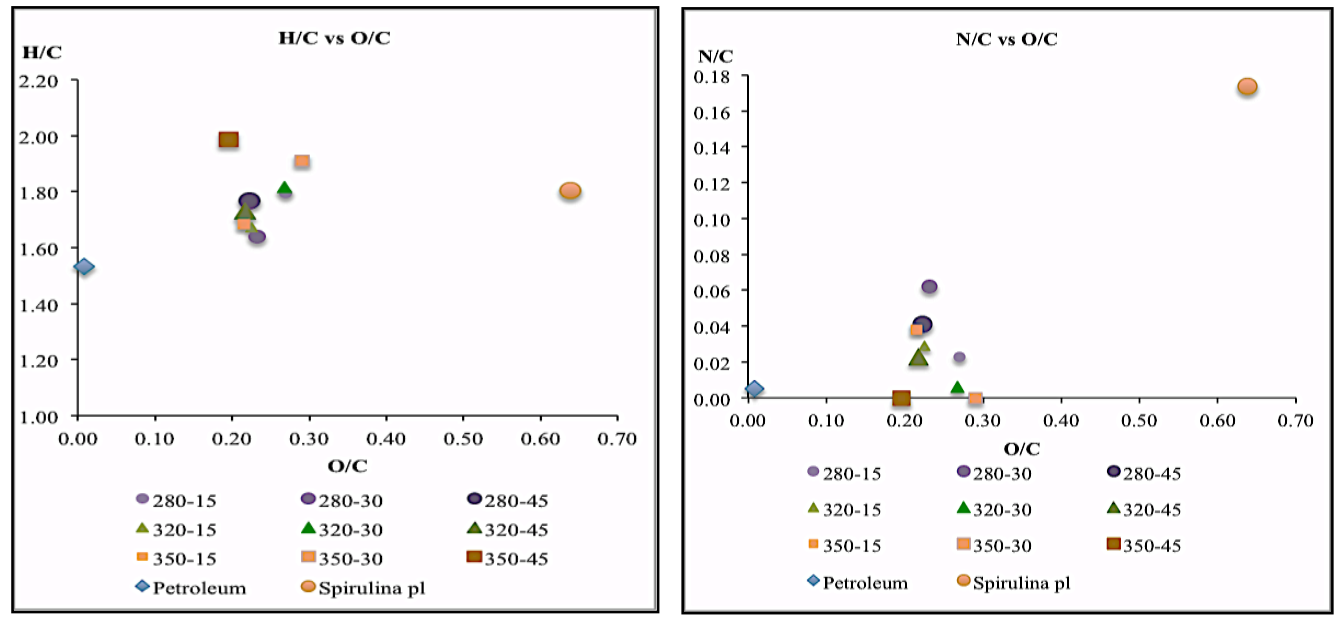

Figure 3 van Krevelen diagram, left: $\mathrm{H} / \mathrm{C}$ vs $\mathrm{O} / \mathrm{C}$, right: N/C vs O/C

The van Krevelen diagram is a good way of showing the relationship between the elemental ratios of biocrude components. The diagram shows the $\mathrm{H} / \mathrm{C}$ vs $\mathrm{O} / \mathrm{C}$ and the N/C vs O/C of HTL biocrude oils. [11] A reference $\mathrm{H} / \mathrm{C}, \mathrm{N} / \mathrm{C}$, and $\mathrm{O} / \mathrm{C}$ of petroleum and the feedstock Spirulina are also plotted. It has a value of $1.532 \mathrm{H} / \mathrm{C}, 0.008 \mathrm{O} / \mathrm{C}$ and $0.005 \mathrm{~N} / \mathrm{C}$. [2] Ideal fuel has high H/C, low O/C and low N/C.

From Figure 3, it is observed that the raw Spirulina has high nitrogen and high oxygen content. After it goes through HTL, the biocrude oils produced have reduced O/C and N/C. This means that the nitrogen and oxygen are removed from the biocrude products. Possible reactions that occur during hydrothermal liquefaction that results to these findings are the decarboxylation and deamination of amino acids produced from protein hydrolysis. The reduced amount of oxygen maybe attributed to gasification. This possibly dominates at high temperature allowing decomposition of compounds into gaseous products. However, the present $\mathrm{N}$ and $\mathrm{O}$ content of the HTL biocrude oils are still higher than that of the commercially used fuel. Thus, further upgrading processes must still be done to the biocrude oil. From the GC-MS analysis of the biocrude oil, it is observed that lots of nitrogen and oxygen containing compounds are present in the biocrude. This supports the $\mathrm{O}$ and $\mathrm{N}$ content of HTL biocrude oil. From the graph of $\mathrm{H} / \mathrm{C}$ vs $\mathrm{O} / \mathrm{C}$, it is observed that the $\mathrm{H} / \mathrm{C}$ of all formed biocrude products have higher values than that of the petroleum. However, the amounts of oxygen are all much higher. The high oxygen might be coming from the formation of ketones, esters, phenols and other oxygen functional groups. The highest $\mathrm{H} / \mathrm{C}$ with the lowest $\mathrm{O} / \mathrm{C}$ is observed in the biocrude oil produced at $350 \mathrm{deg} \mathrm{C}$ and 45 mins of reaction time. The $\mathrm{H} / \mathrm{C}$ value is almost 2 while the $\mathrm{O} / \mathrm{C}$ value is 0.2 . Looking at the $\mathrm{N} / \mathrm{C}$ plot, generally, most of the biocrude oils have higher nitrogen content than the commercial petroleum. It can be noticed as well that there are conditions at which the nitrogen content of the biocrude is lower or almost similar to that of commercial petroleum crude. This occurs at the highest temperature setting, $350 \mathrm{deg} \mathrm{C}$ and at longest reaction times, which are $45 \mathrm{mins}$ and 30 mins. Also from the graph, it can be noticed that at $280 \mathrm{deg} \mathrm{C}$, biocrude oil 
produced by HTL has higher nitrogen content. Although the $\mathrm{H} / \mathrm{C}$ of biocrude at $350 \mathrm{deg} \mathrm{C}$ and 30 mins is high and the nitrogen content is low, it is observed that the $\mathrm{O} / \mathrm{C}$ ratio is still high.

\subsection{Effects on Composition based on GCMS Analysis}

Determining the components in the biocrude oils produced by HTL will give hints on the chemical properties of the biocrude oil produced. Biocrude oil products analyzed across reaction time are those processed at $280 \mathrm{deg}$. At this temperature, high mass yields are observed. Samples analyzed across temperature are biocrude oils processed at 30 mins. It is observed that the energy yields at this reaction time are comparable. Based on the details of compounds reported, Table 2 shows the major compounds that are found in the biocrude oils at different conditions.

Table 2 Most abundant components in HTL biocrude oil at different conditions

\begin{tabular}{|c|c|c|c|c|}
\hline $280 \operatorname{deg} \mathrm{C}$ & $280 \operatorname{deg} \mathrm{C}$ & $280 \operatorname{deg} \mathrm{C}$ & $320 \operatorname{deg} \mathrm{C}$ & $350 \operatorname{deg} \mathrm{C}$ \\
\hline 15 mins & $30 \mathrm{mins}$ & 45 mins & 30 mins & $30 \mathrm{mins}$ \\
\hline Heptadecane & $\begin{array}{l}\text { Hexanoic acid, } \\
\text { morpholide }\end{array}$ & Heptadecane & sec-Butyl nitrite & sec-Butyl nitrite \\
\hline Hexane, 2-nitro- & Heptadecane & $\begin{array}{l}\text { Hydroperoxide, } 1- \\
\text { ethylbutyl }\end{array}$ & $\begin{array}{l}\text { 2-Hexanone, 3,3- } \\
\text { dimethyl- }\end{array}$ & 2-Hexanone \\
\hline $\begin{array}{l}\text { Hexanoic acid, } \\
\text { morpholide }\end{array}$ & $\begin{array}{l}\text { Hydroperoxide, 1- } \\
\text { ethylbutyl }\end{array}$ & sec-Butyl nitrite & Heptadecane & $\begin{array}{l}\text { 3,3-dimethyl-, } \\
\text { Heptadecane }\end{array}$ \\
\hline $\begin{array}{l}\text { 2-Hexanone, 3,3- } \\
\text { dimethyl- }\end{array}$ & sec-Butyl nitrite & $\begin{array}{l}\text { Hexanoic acid, } \\
\text { morpholide }\end{array}$ & Hexadecanamide & Hexadecanamide \\
\hline $\begin{array}{l}\mathrm{N}- \\
\text { Methyldodecanamide }\end{array}$ & $\begin{array}{l}\text { Octadecanamide, } \mathrm{N}- \\
\text { butyl- }\end{array}$ & N-Methyldodecanamide & $\begin{array}{l}\text { 2-Pyrrolidinone, 1- } \\
\text { butyl- }\end{array}$ & Eicosane \\
\hline $\begin{array}{l}\mathrm{N}, \mathrm{N}- \\
\text { Dimethyldodecanamide }\end{array}$ & $\begin{array}{l}\mathrm{N}, \mathrm{N}- \\
\text { Dimethyldodecanamide }\end{array}$ & $\begin{array}{l}\mathrm{N}, \mathrm{N}- \\
\text { Dimethyldodecanamide }\end{array}$ & Eicosane & $\begin{array}{l}\text { 2-Pyrrolidinone, } \\
\text { 1-butyl- }\end{array}$ \\
\hline $\begin{array}{l}\text { Octadecanamide, } \mathrm{N}- \\
\text { butyl- }\end{array}$ & $\begin{array}{l}\mathrm{N}- \\
\text { Methyldodecanamide }\end{array}$ & Eicosane & $\begin{array}{l}\text { Hexanoic acid, } \\
\text { phenyl ester }\end{array}$ & \\
\hline $\begin{array}{l}\text { 2-Hexadecene, } \\
\text { 3,7,11,15-tetramethyl-, } \\
{\left[\mathrm{R}-\left[\mathrm{R}^{*}, \mathrm{R}^{*} \text {-( }\right.\right.}\end{array}$ & $\begin{array}{l}\text { 2-Hexadecene, } \\
\text { 3,7,11,15-tetramethyl-, } \\
{\left[\mathrm{R}-\left[\mathrm{R}^{*}\right.\right.}\end{array}$ & $\begin{array}{l}\text { 2-Hexadecene, } 3,7,11,15- \\
\text { tetramethyl-, [R-[R*, } \mathrm{R}^{*} \text {-( }\end{array}$ & $\begin{array}{l}\mathrm{N}- \\
\text { Methyldodecanamide }\end{array}$ & \\
\hline Hexadecanamide & & Octadecanamide, N-butyl- & $\begin{array}{l}\text { 3-Allyl-6- } \\
\text { methoxyphenol }\end{array}$ & \\
\hline $\begin{array}{l}\text { Hexanoic acid, phenyl } \\
\text { ester }\end{array}$ & & Cyclo-(glycyl-1-leucyl) & & \\
\hline \multirow[t]{2}{*}{ Eicosane } & & Hexadecanamide & & \\
\hline & & $\begin{array}{l}\mathrm{N}-[2- \\
\text { Hydroxyethyl] succinimide }\end{array}$ & & \\
\hline
\end{tabular}

To better understand the properties of the biocrude, the components are classified according to its corresponding organic functional group. The same group classification exhibit similar characteristic properties. The functional groups of the compounds are hydrocarbons, which include alkanes, alkenes, aromatics; nitrogen containing compounds like amides, amines, nitriles and nitrites; oxygenated compounds like carboxylic acids, esters alcohols and ketones. The relative percent peak area of the components reported from GC-MS is plotted in Figure 4. This shows the abundance of each group of components. 


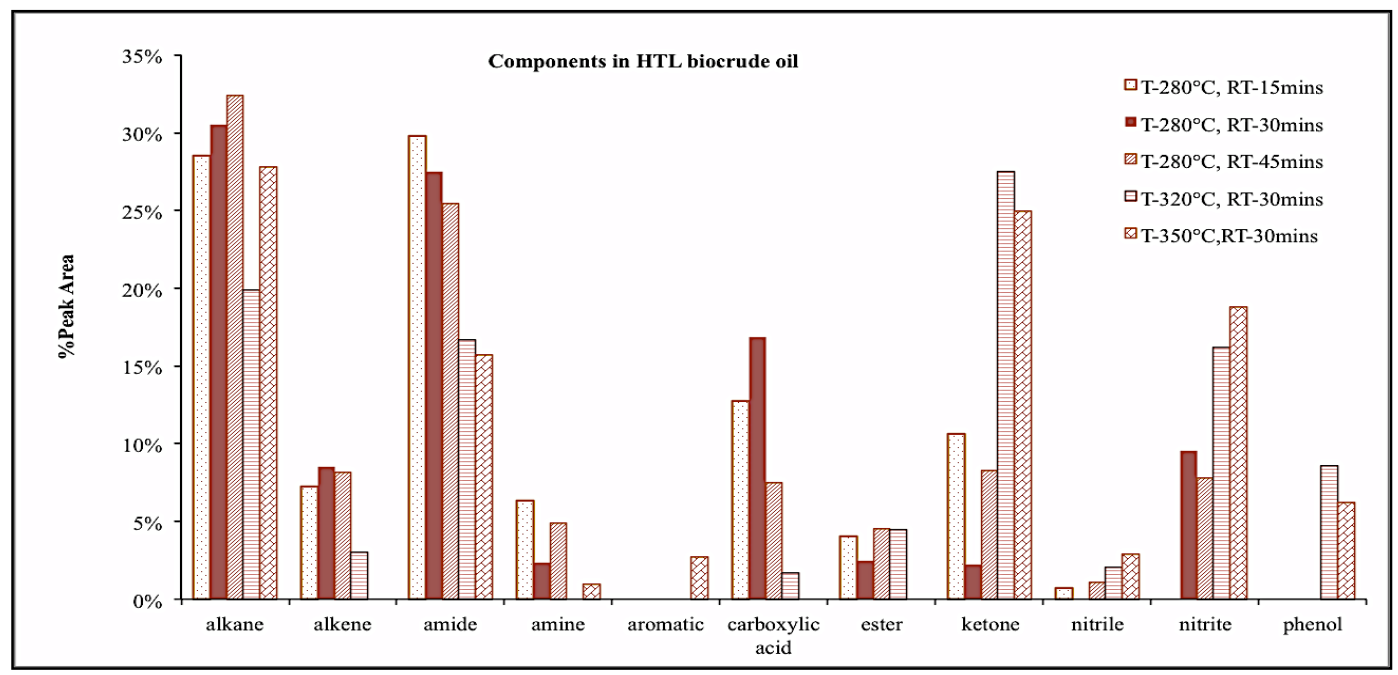

Figure 4. Components in HTL biocrude oil

It is observed that hydrocarbons are abundant in all biocrude oils at different conditions. This is a major component in biofuels. Fatty acids are also observed in the biocrude. Higher yield is observed at lower temperature. The high viscosity of the biocrude oil produced is attributed to the presence of long chained fatty acids and the long chained hydrocarbons. [4] Alkenes are observed to be decreasing as the temperature is increasing. Probable reason is the breaking of bonds forming other compounds. Phenols are produced at temperature setting of $320 \mathrm{deg} C$ and $350 \mathrm{deg}$ C. Phenols are converted by HTL from the carbohydrate content of microalgae. Another possible mechanism is formation via glucose first before transforming into phenols. Also at temperature above $300 \mathrm{deg} \mathrm{C}$, aromatic compounds are found in the biocrude. Aromatic compounds contribute the heavy fuel portion of the biocrude. At higher temperatures, polycyclic aromatic hydrocarbons are usually observed. At the lowest temperature and time setting, nitrites are not yet formed but as the time and temperature go higher, nitrites increased. Amides are remarkably high in all conditions. This contributes to the high nitrogen content of biocrude oil. However, it is decreased at $320 \mathrm{deg} \mathrm{C}$ and at $350 \mathrm{deg} \mathrm{C}$. The thermal decomposition of amino acids may produce other nitrogen containing organic compounds. For oxygenates, the carboxylic acid is significantly decreased. Reduction of the carboxylic acids may have occurred. Ketones increased at higher temperatures. Oxygenates contribute to the relatively high oxygen of content in HTL biocrude oil. The knowledge of the $\mathrm{N}$ and $\mathrm{O}$ containing compounds present in the biocrude oil helps in the approach to upgrading the biocrude oil to reduce the $\mathrm{N}$ and $\mathrm{O}$ content.

\section{Conclusion}

Hydrothermal liquefaction of Spirulina platensis produced biocrude of yields that range from $30 \%$ to $46 \%$ by weight. Temperature is found to have significant effect on the mass yield of biocrude while reaction time does not have significant effect. Higher mass yield of biocrude is found to be consistently high at the lowest temperature condition tested. Biocrude yield is lower at higher temperature settings.

HHV is highest at higher temperature and longer reaction time. Across tested temperature, there is no significant difference found in the HHV values of biocrude. Reaction time however has significant effect observed especially at lower temperature condition. Higher energy yield is observed at lower temperature and longer reaction time.

As for the composition, the biocrude produced has significantly lower oxygen and nitrogen content compared to raw feedstock. However, it still has high $\mathrm{O}$ and $\mathrm{N}$ content when compared to commercial 
petrocrude. At higher temperature, formation of oxygen-containing compounds is observed. Nitrogen content of biocrude is reduced at higher temperature.

It is concluded that temperature and reaction time conditions have certain effects on the mass yield, the HHV, energy recovery, and the composition of the biocrude oil produced. The information gathered from the research could be used in further development of the HTL process of biomass.

\section{References}

[1] P. Basu, Biomass Gasification and Pyrolysis Handbook. 2010.

[2] B. Eboibi, D. Lewis, P. Ashman, and S. Chinnasamy, "Effect of operating conditions on yield and quality of biocrudo during hydrothermal liquefaction of halophytic microalga Tetraselmis sp," Bioresour. Technol., vol. 170, pp. 20-29, 2014.

[3] M. Lavanya et al., "Hydrothermal liquefaction of freshwater and marine algal biomass: A novel approach to produce distillate fuel fractions through blending and co-processing of biocrude with petrocrude," Bioresour. Technol., vol. 203, pp. 228-235, 2016.

[4] J. A. Ramirez, R. J. Brown, and T. J. Rainey, "A review of hydrothermal liquefaction bio-crude properties and prospects for upgrading to transportation fuels," Energies, vol. 8, no. 7, pp. 6765-6794, 2015.

[5] S. S. Toor, L. Rosendahl, and A. Rudolf, "Hydrothermal liquefaction of biomass: A review of subcritical water technologies," Energy, vol. 36, no. 5, pp. 2328-2342, 2011.

[6] Y. Guo, T. Yeh, W. Song, D. Xu, and S. Wang, "A review of bio-oil production from hydrothermal liquefaction of algae," Renew. Sustain. Energy Rev., vol. 48, pp. 776-790, 2015.

[7] H. K. Reddy et al., "Temperature effect on hydrothermal liquefaction of Nannochloropsis gaditana and Chlorella sp.," Appl. Energy, vol. 165, pp. 943-951, 2016.

[8] D. L. Barreiro, "Hydrothermal Liquefaction ( HTL ) of Microalgae for Biofuel Production: State of the Art Review and Future Prospects," vol. 53, no. February, 2013.

[9] Z. Wang, S. Adhikari, P. Valdez, R. Shakya, and C. Laird, "Upgrading of hydrothermal liquefaction biocrude from algae grown in municipal wastewater," Fuel Process. Technol., vol. 142, pp. 147-156, 2016.

[10] D. C. Elliott et al., "Process development for hydrothermal liquefaction of algae feedstocks in a continuous-flow reactor," Algal Res., vol. 2, no. 4, pp. 445-454, 2013.

[11] F. M. Hossain et al., "Experimental Investigations of Physical and Chemical Large Batch Reactor," pp. 1-16, 1977.

[12] P. Biller, B. K. Sharma, B. Kunwar, and A. B. Ross, "Hydroprocessing of bio-crude from continuous hydrothermal liquefaction of microalgae," Fuel, vol. 159, pp. 197-205, 2015.

[13] K. R. Arturi, S. Kucheryavskiy, and E. G. Søgaard, "Performance of hydrothermal liquefaction (HTL) of biomass by multivariate data analysis," Fuel Process. Technol., vol. 150, pp. 94-103, 2016.

[14] J. Zhang, W. Chen, P. Zhang, Z. Luo, and Y. Zhang, "Bioresource Technology Hydrothermal liquefaction of Chlorella pyrenoidosa in sub- and supercritical ethanol with heterogeneous catalysts," Bioresour. Technol., vol. 133, pp. 389-397, 2013.

[15] A. Habib and M. Parvin, a Review on Culture, Production and Use of Spirulina As Food for Humans and Feeds for, vol. 1034, no. 1034. 2008.

[16] P. Biller and A. B. Ross, "Potential yields and properties of oil from the hydrothermal liquefaction of microalgae with different biochemical content," Bioresour. Technol., vol. 102, no. 1, pp. 215-225, 2011.

[17] D. R. Vardon et al., "Chemical properties of biocrude oil from the hydrothermal liquefaction of Spirulina algae, swine manure, and digested anaerobic sludge," Bioresour. Technol., vol. 102, no. 17, pp. 8295-8303, 2011.

[18] P. J. Valdez, M. C. Nelson, H. Y. Wang, X. N. Lin, and P. E. Savage, "Hydrothermal liquefaction of Nannochloropsis sp.: Systematic study of process variables and analysis of the product fractions," Biomass and Bioenergy, vol. 46, pp. 317-331, 2012. 